\title{
Rhodium(III) complex with pyrene-pyridyl-hydrazone: synthesis, structure, ligand redox, spectral characterization and DFT calculation
}

\author{
SOUMITRA DINDA ${ }^{\mathrm{a}}$, SARAT CHANDRA PATRA $^{\mathrm{b}}$ and SANJIB GANGULY ${ }^{\mathrm{a}, *(\mathbb{C})}$ \\ ${ }^{a}$ Department of Chemistry, St. Xavier's College (Autonomous), Kolkata, West Bengal 700 016, India \\ ${ }^{b}$ Department of Chemistry, Jadavpur University, Kolkata, West Bengal 700 032, India \\ E-mail: icsgxav@gmail.com; icsg@sxccal.edu
}

MS received 16 November 2018; revised 31 January 2019; accepted 3 February 2019; published online 7 March 2019

\begin{abstract}
The pyridylhydrazone ligand incorporating a pendant pyrene moiety HL has been synthesized starting from 2-hydrazinopyridine and its coordinating behaviour towards rhodium(III) have been scrutinized. The complex of type $\left[\mathrm{Rh} \mathbf{L}\left(\mathrm{PPh}_{3}\right)_{2} \mathrm{Cl}_{2}\right]$, incorporating five-membered chelate ring has been isolated and the structure has been authenticated by single-crystal X-ray diffraction study. The ligand exhibits an oxidative response at $\sim 1.2 \mathrm{~V}$ upon coordination with rhodium(III) and the optoelectronic properties as well as theoretical exploration have been performed by the density functional theory (DFT) as well as time-dependent density functional theory (TD-DFT) analyses.
\end{abstract}

Keywords. Polycyclic aromatic hydrocarbon (PAH); hydrazone; photoluminescence; redox activity.

\section{Introduction}

Metal complexes of Schiff bases have been comprehensively used as building blocks to fabricate a large variety of topologies. Among them, hydrazones have captivated the researchers due to their illustrious aptitude towards chelation, biological activities as well as due to their structural flexibility that can provide rigidity to the synthesized metal-ligand scaffold. ${ }^{1-18}$ Hydrazones can generate an environment comparable to the one present in biological systems usually by coordination through oxygen and nitrogen atoms. A variety of significant characteristics of carbonic acid hydrazides, along with their applications in medicine and analytical chemistry have led to significant awareness in their complexation characteristics with transition metal ions. ${ }^{19-23}$

In recent times, it has been authenticated that the $\mathrm{N}-\mathrm{N}$ bond in the hydrazones participates as a key activating unit and plays a decisive role as Lewis base that emerges as a directing group (DG) towards rhodiumcatalyzed $\mathrm{C}-\mathrm{H}$ activation reactions. ${ }^{24-26}$ It has been further validated that $\mathrm{Rh}$ (III) is connected to the $\mathrm{N}$-atoms of the hydrazone group during the catalytic cycle. ${ }^{24}$ In

\footnotetext{
*For correspondence
}

this connection, the exploration of the molecular and electronic structures of novel rhodium(III) hydrazone complex is imperative for the search of suitable electron transfer as well as optoelectronic characteristics within the metal-organic framework. In this paper, we report the designed synthesis of a new pyridylhydrazone ligand incorporating a pendant pyrene group, 1 (Scheme 1) starting from 2 -hydrazinopyridine. The rhodium (III) complex 2 has been synthesized and it has been observed that the ligand and the complex is emissive in nature. The rhodium complex has been characterized comprehensively by X-ray diffractometry which discloses the formation of a five-member metallacycle. Spectral characterization, as well as theoretical analysis of 2 , has been reported extensively. An additional remarkable feature in the complex is that the ligand framework can function as an electron donor upon coordination and this has been corroborated from the nature of the redox orbitals.

\section{Experimental}

\subsection{General}

The chemicals used in this work were purchased from the following sources: 2 hydrazinopyridine from TCI Chemicals 


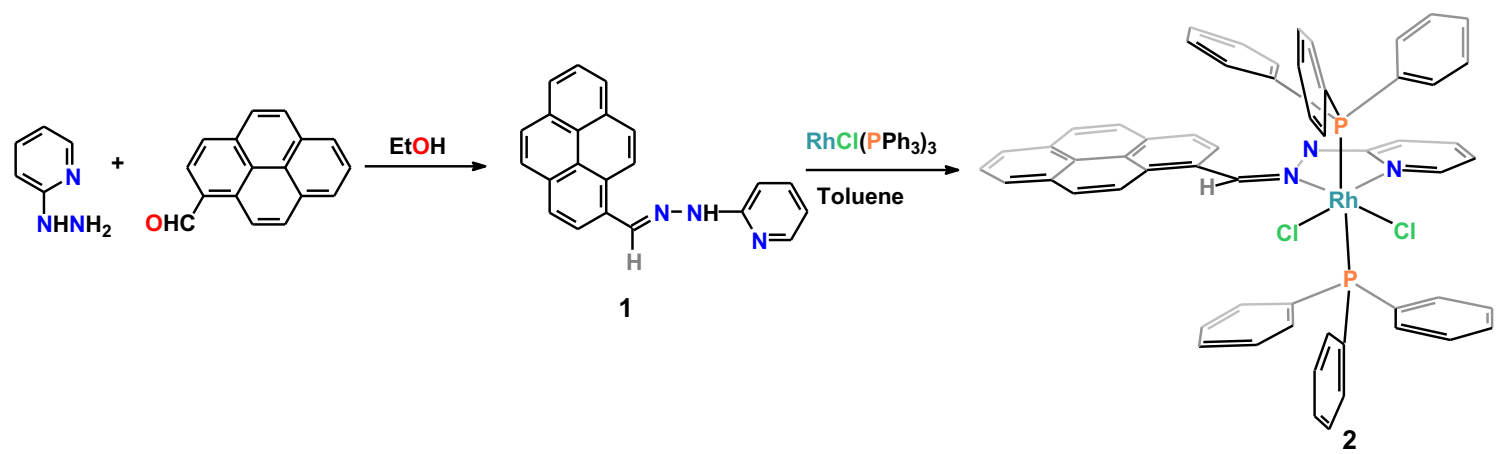

Scheme 1. Synthesis of ligand $\mathbf{1}$ and complex $\mathbf{2}$ starting from 2-hydrazinopyridine.

(India) Pvt. Ltd.; 1-pyrenecarboxaldehyde was procured from Alfa Aesar. Triphenylphosphine was purchased from Sigma Aldrich, India. Rhodium trichloride salt was purchased from Arora Matthey Pvt. Ltd. All solvents and the chemicals were utilized as received, without further purifications. UV-vis spectra were recorded on a Perkin Elmer LAMBDA 25 spectrophotometer. ${ }^{1} \mathrm{H}$ NMR spectra were measured on Bruker FT 500 and ${ }^{13} \mathrm{C}$-NMR was measured on Bruker FT 400 operating at frequencies 100 and $150 \mathrm{MHz}$ respectively (Figures S4-S7, Supplementary Information). ${ }^{31}$ P-NMR of 2 was measured on Bruker FT $400 \mathrm{MHz}$ spectrometer which operates at 161.99 MHz (Figure S8, Supplementary Information). Elemental analyses $(\mathrm{C}, \mathrm{H}, \mathrm{N})$ were performed on a Perkin Elmer 2400 series II analyzer and electrochemical measurements were recorded on a Versa Stat II Princeton Applied Research potentiostat/galvanostat using a platinum electrode under an argon atmosphere. Tetrabutylammoniumhexafluorophosphate $\left(\left[\mathrm{N}(\mathrm{n}-\mathrm{Bu})_{4}\right] \mathrm{PF}_{6}\right)$ was used as a supporting electrolyte and potentials were referenced to the $\mathrm{Ag} / \mathrm{AgCl}$ electrode without junction correction. The emission data were collected on a Perkin Elmer LS 55 fluorescence spectrometer. For all luminescence measurements, excitation and emission slit widths of $4 \mathrm{~nm}$ were used. Quantum yields of the complex were determined at $25^{\circ} \mathrm{C}$ in freeze-pump-thaw degassed solutions of dichloromethane. Anthracene in ethanol is used as the standard during quantum yield measurement for compounds. ${ }^{27,28}$ The quantum yields were calculated using eqn (1). ${ }^{26}$

$$
\Phi_{\mathrm{r}}=\Phi_{\text {std }} \frac{A_{\text {std }} I_{\mathrm{r}} \eta_{\mathrm{r}}^{2}}{A_{\mathrm{r}} I_{\mathrm{std}} \eta_{\text {std }}^{2}}
$$

Where $\Phi_{\mathrm{r}}$ and $\Phi_{\text {std }}$ are the quantum yields of an unknown and standard sample ( $\Phi_{\text {std }}=0.270$ for anthracene $), \mathrm{A}_{\mathrm{r}}$ and $A_{\text {std }}$ are the solution absorbances at the excitation wavelength $\left(\lambda_{\mathrm{ex}}\right), \mathrm{I}_{\mathrm{r}}$ and $\mathrm{I}_{\text {std }}$ are the integrated emission intensities, and $\eta_{\mathrm{r}}$ and $\eta_{\mathrm{std}}$ are the refractive indices of the solvents. Timecorrelated single-photon counting (TCSPC) measurements were carried out for the luminescence decay of Ligand $\mathbf{1}$ complex $\mathbf{2}$ in dichloromethane. For TCSPC measurement, the photoexcitation was done at 300 and $330 \mathrm{~nm}$ using two picosecond diode laser (IBH Nanoled-07) in an IBH Fluorocube apparatus. The fluorescence decay data were collected on a Hamamatsu MCP photomultiplier (R3809) and were analyzed by using IBHDAS6 software. X-ray intensity data for 2 was measured at 293(2) K on a Bruker AXS SMART APEX CCD diffractometer using Mo $\mathrm{K} \alpha(\lambda=0.71073 \AA$ ). Metal atoms were located by direct methods, and the rest of the non-hydrogen atoms emerged from successive Fourier synthesis. The structures were refined by full-matrix least-squares procedures on F2. The hydrogen atoms were included in calculated positions and treated as riding atoms using SHELXL default parameters. Calculations were performed using the SHELXTL V 6.14 program package. ${ }^{30}$ Thermal ellipsoids were drawn at the $50 \%$ probability level. Molecular structure plots were drawn using the Oak Ridge thermal ellipsoid plot ORTEP. ${ }^{31}$ Hydrogen atoms were kept fixed using the riding model during refinement. Crystallographic data and refinements for the complex is presented in SI (Table S1, Supplementary Information $\dagger$ ). The ORTEP plot is presented in Figure 1.

\subsection{Computational study}

The molecular geometries of the singlet ground state $\left(\mathrm{S}_{0}\right)$ of the synthesized complex 2 have been calculated by the DFT method using the (R)B3LYP ${ }^{32,33}$ hybrid functional approach incorporated into the GAUSSIAN 09 program package. ${ }^{34}$ The geometries of the complex were fully optimized in the gas phase without imposing any symmetry constraints. The nature of all the stationary points was checked by computing vibrational frequencies, and all the species were found to be true potential energy minima, as no imaginary frequency was obtained (NImag $=0$ ). The single crystal X-ray coordinates have been used as the initial input in all calculations for 2 . On the basis of the optimized ground and excited state geometries, the absorption and emission spectra properties in dichloromethane $\left(\mathrm{CH}_{2} \mathrm{Cl}_{2}\right)$ media were calculated by the time-dependent density functional theory (TD-DFT) ${ }^{35-38}$ approach associated with the conductor-like polarizable continuum model (CPCM). ${ }^{39-41}$ We computed the lowest 200 singlet-singlet transitions and singlet-triplet transitions each in absorption and emission processes, respectively and the results of the TD calculations were qualitatively similar to the observed spectra. The TD-DFT approach is now 
well-known as a rigorous formalism for the treatment of electronic excitation energies within the DFT framework for calculating spectral properties of many transition metal complexes. ${ }^{42-45}$ Hence TD-DFT had been shown to provide a reasonable spectral feature for the compound under investigation. The rhodium atom was described by a double- $\zeta$ basis set with the effective core potential of Hay and Wadt (LANL2DZ), ${ }^{46,47}$ and the $6-31 \mathrm{G}$ basis set ${ }^{48,49}$ was used for the other elements present in the complex to optimize both ground state and the lowest lying triplet excited state geometries. The calculated electronic density plots for frontier molecular orbitals were prepared by using the Gauss View 5.0 software. The GaussSum program, version 2.2, ${ }^{50}$ was used to calculate the molecular orbital contributions from groups or atoms.

\subsection{Syntheses of the ligand}

2-(2-(pyren-1-ylmethylene)hydrazinyl)pyridine, HL (1): To an ethanolic solution of 1- pyrenecarboxaldehyde (460.5 mg, $2.0 \mathrm{mmol}$ ) was added 2-hydrazinopyridine (218.3 $\mathrm{mg}, 2.0 \mathrm{mmol}$ ) in ethanol and the resulting mixture was stirred for $3 \mathrm{~h}$. A yellow solid was separated, which was filtered and dried in vacuum over fused calcium chloride. Yield: $500 \mathrm{mg}$ (78\%). Anal. Calcd (\%) for $1, \mathrm{C}_{22} \mathrm{H}_{15} \mathrm{~N}_{3}$ : C, 82.22; $\mathrm{H}, 4.70 ; \mathrm{N}, 13.08$. Found: C, 82.12; H, 4.66; N, 13.11. HRMS: $m / z=322.1638$ (calcd. 322.1344) (Figure S5, Supplementary Information); FT-IR $\left(\mathrm{cm}^{-1}\right): 1610\left(\mathrm{~s}, v_{\mathrm{C}=\mathrm{N}}\right) ;{ }^{1} \mathrm{H}$ NMR $\left(\mathrm{CDCl}_{3}, 500 \mathrm{MHz}\right)$, $(\delta, \mathrm{ppm})=10.81(\mathrm{~s}, 1 \mathrm{H}), 8.74(\mathrm{~d}, J=9.0 \mathrm{~Hz}, 3 \mathrm{H}), 8.57$ $(\mathrm{d}, 8.0 \mathrm{~Hz}, 1 \mathrm{H}), 8.20\left(\mathrm{dd}, J_{1}=8.0 \mathrm{~Hz}, J_{2}=9 \mathrm{~Hz}, 4 \mathrm{H}\right)$, $8.11-8.01(\mathrm{~m}, 3 \mathrm{H}), 7.71-7.67(\mathrm{~m}, 1 \mathrm{H}), 7.54(\mathrm{~d}, J=8.5 \mathrm{~Hz}$, $1 \mathrm{H}), 6.83(\mathrm{~s}, 1 \mathrm{H}) ;{ }^{13} \mathrm{C}-\mathrm{NMR}\left(150 \mathrm{MHz}, \mathrm{CDCl}_{3}\right):(\delta, \mathrm{ppm})=$ $193.08,135.61,131.37,131.17,131.07,130.87,130.77$, $130.54,128.35,127.98,127.55,127.28,127.13,126.93$, $126.66,125.76,125.43,124.75,124.62,124.17,123.09$, 122.63 .

\subsection{Synthesis of the complex}

[RhL( $\left.\mathbf{P P h})_{2} \mathbf{C l}_{2}\right]$ (2): To a solution of $32.2 \mathrm{mg}(0.1 \mathrm{mmol})$ of 1 in $25 \mathrm{~mL}$ of dry toluene was added $90 \mathrm{mg}(0.097 \mathrm{mmol})$ of $\left[\mathrm{Rh}\left(\mathrm{PPh}_{3}\right)_{3} \mathrm{Cl}\right]$ and the reaction mixture was refluxed for $5 \mathrm{~h}$. The red solution so formed was allowed to cool and the dark orange solid was filtered off. The residue was dried in vacuum. Diffusion of dichloromethane solution of the complex into n-hexane afforded single crystal of $\mathbf{2}$. Yield: $36 \mathrm{mg}(35 \%)$. Anal. Calcd (\%) for $1 \mathrm{a} \mathrm{C}_{58} \mathrm{H}_{44} \mathrm{~N}_{3} \mathrm{P}_{2} \mathrm{Cl}_{2} \mathrm{Rh}$ : C,68.38; H, 4.35; N, 4.12. Found: C, 68.25; H, 4.31; N, 4.15. HRMS: $m / z=1018.5782$ (calcd. 1018.1521); FTIR $\left(\mathrm{cm}^{-1}\right)$ : $1603\left(\mathrm{~m}, v_{\mathrm{C}=\mathrm{N}}\right) ; 687\left(\mathrm{vs}, \boldsymbol{v}_{\mathrm{Rh}-\mathrm{P}(\mathrm{sym})}\right), 518$ (vs, $\left.\nu_{\mathrm{Rh}-\mathrm{P}(\text { asym })}\right) ;{ }^{1} \mathrm{H} \mathrm{NMR}\left(500 \mathrm{MHz}, \mathrm{CDCl}_{3}\right):(\delta, \mathrm{ppm})=$ $8.30(\mathrm{~m}, 1 \mathrm{H}), 8.14(\mathrm{~m}, 3 \mathrm{H}), 8.03-7.99(\mathrm{~m}, 4 \mathrm{H}), 7.90-7.89$ $(\mathrm{m}, 4 \mathrm{H}), 7.73-7.68(\mathrm{~m}, 9 \mathrm{H}), 7.48-7.46(\mathrm{~m}, 5 \mathrm{H}), 7.08(\mathrm{~d}$, $J=7.0 \mathrm{~Hz}, 3 \mathrm{H}), 7.05-6.99(\mathrm{~m}, 11 \mathrm{H}), 6.79(\mathrm{~m}, 1 \mathrm{H}), 6.55$ $(\mathrm{d}, J=9 \mathrm{~Hz}, 1 \mathrm{H}), 6.43(\mathrm{~d}, J=8.5 \mathrm{~Hz}, 1 \mathrm{H}), 5.32(\mathrm{~s}$, $1 \mathrm{H}) ;{ }^{13} \mathrm{C}-\mathrm{NMR}\left(100 \mathrm{MHz}, \mathrm{CDCl}_{3}\right):(\delta, \mathrm{ppm})=135.44$, $135.11,135.06,135.01,132.32,132.22,132.10,132.07$,

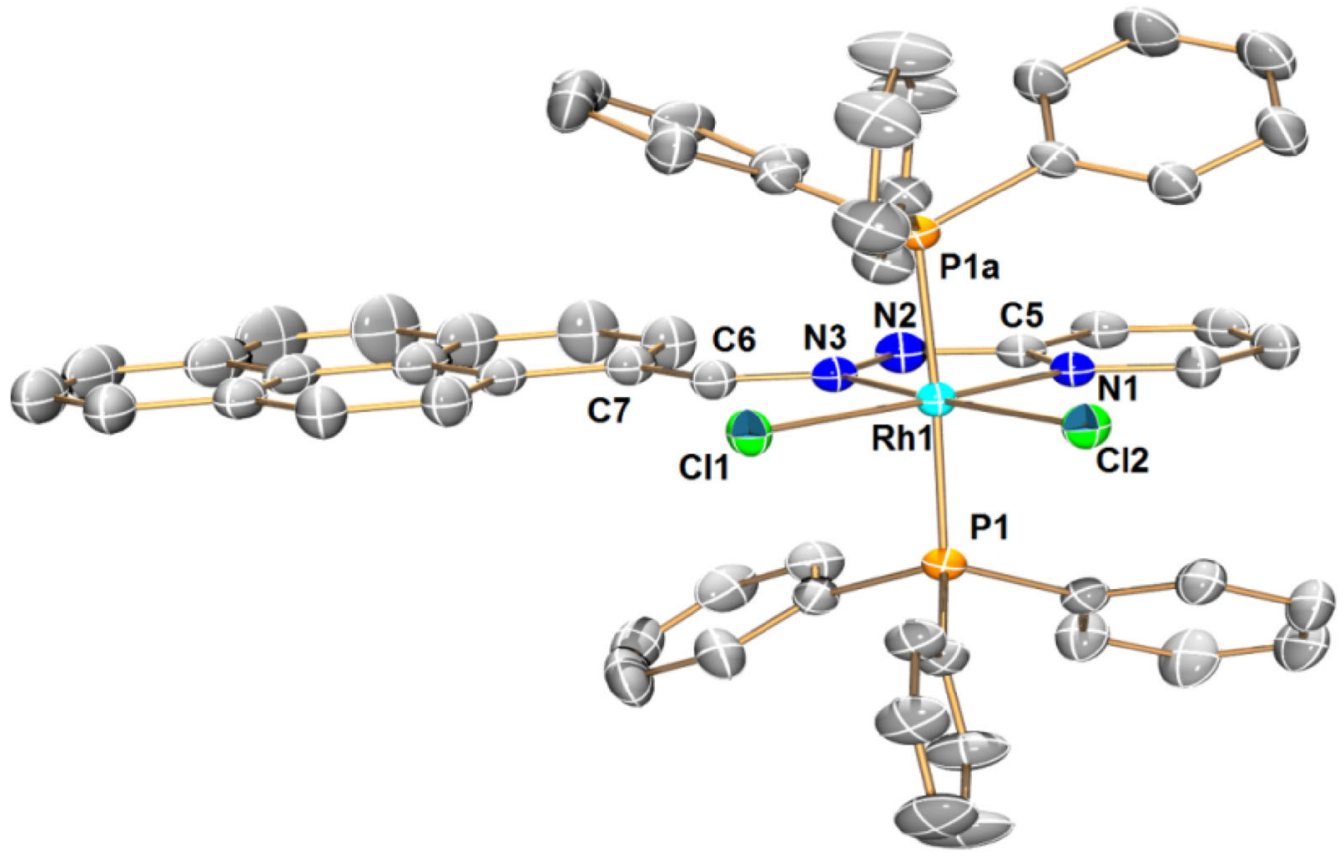

Figure 1. ORTEP view of 2a: Hydrogen atoms are omitted for clarity, and thermal ellipsoids are set at 50\% probability. Selected bond lengths ( $\AA$ ) and angles (deg): Rh1-N1 2.0257(17), Rh1-N3 2.0336(16), Rh1-Cl1 2.3872(5), Rh1-Cl2 2.3842(5), Rh1-P1 2.3924(4), Rh1-P1a 2.3923(4), N2-N3 1.370(2), N2-C5 1.333(3), N1-C5 1.372(3), N3-C6 1.304(3); N1-Rh1-Cl2 93.91(5), N1-Rh1-N3 79.03(7), N3-Rh1-Cl1 93.96(5), Cl2-Rh1-Cl1 93.10(19). 
$129.90,129.33,129.09,128.70,128.60,128.06,127.90$, $127.81,127.76,127.72,127.50,127.40,125.35 ;{ }^{31} \mathrm{P} \mathrm{NMR}$ $\left(161.99 \mathrm{MHz}, \mathrm{CDCl}_{3}\right): \delta 30.74\left(\mathrm{~d},{ }^{1} \mathrm{~J}_{R h-P}=144.17 \mathrm{~Hz}\right.$, $\left.\mathrm{PPh}_{3}\right)$.

\section{Results and Discussion}

\subsection{Synthesis and structure}

The ligand HL, 1 used in the current work has been synthesized by refluxing 2-hydrazinopyridine with 1pyrenecarboxaldehyde $(1: 1$ molar ratio) in ethanol. It provides three different types of donor $\mathrm{N}$-atoms among which the pyridyl-N and one of the hydrazonyl-N atoms behave as donor centres during coordination. Upon refluxing a solution of $\mathbf{1}$ in toluene with Wilkinson's catalyst in 1:1 molar ratio, a dark red coloured solution was obtained which was further evaporated in vacuo and chromatographed to obtain $\left[\mathrm{Rh} L\left(\mathrm{PPh}_{3}\right)_{2} \mathrm{Cl}_{2}\right], \mathbf{2}$ in good yields. The mode of chelation is shown in Scheme 1 , where the ligand forms a five-member ring with rhodium(III) in 2. During the course of the reaction, the ligand loses a hydrazonyl proton, while the square planar $\mathrm{Rh}(\mathrm{I})$ loses electrons thereby forming $\left[\mathrm{Rh} \mathbf{L}(\mathrm{PPh} 3)_{2} \mathrm{Cl}_{2}\right]$ and hence it may be considered as an example of oxidative coordination reaction.

The complex 2 crystallizes in monoclinic C $2 / \mathrm{m}$ space group and the ORTEP view is depicted in Figure 1. The $\mathrm{X}$-ray structure revealed that the ligand binds as bidentate uninegative with the pyridyl-N and a hydrazonyl-N linked to rhodium(III), thereby forming a stable fivemember chelate ring and the metal center is in a distorted octahedral environment. The $\mathrm{N}-\mathrm{N}$ length in the complex has been found to be 1.370(2), and this is indicative of the single bond character. The $\mathrm{Cl}$ atoms are cis with respect to each other and both the $\mathrm{Rh}-\mathrm{Cl}$ lengths in the complex are nearly equal. The crystallographic parameters of $\mathbf{2}$ are listed in Table S2, Supplementary Information.

\subsection{Ground state geometries and frontier molecular orbital compositions}

The complex $\mathbf{2}$ has been found to be diamagnetic with singlet ground state $\left(t_{2}^{6}\right)$ as expected for rhodium(III). The geometry optimization was performed using the crystallographic coordinates at (R)B3LYP levels in the gas phase in its singlet spin state without any ligand simplification. The optimized geometry is shown in Figure 2, and the significant calculated metrical parameters are listed in Table 1 along with a comparison with the experimental value. The optimized structural

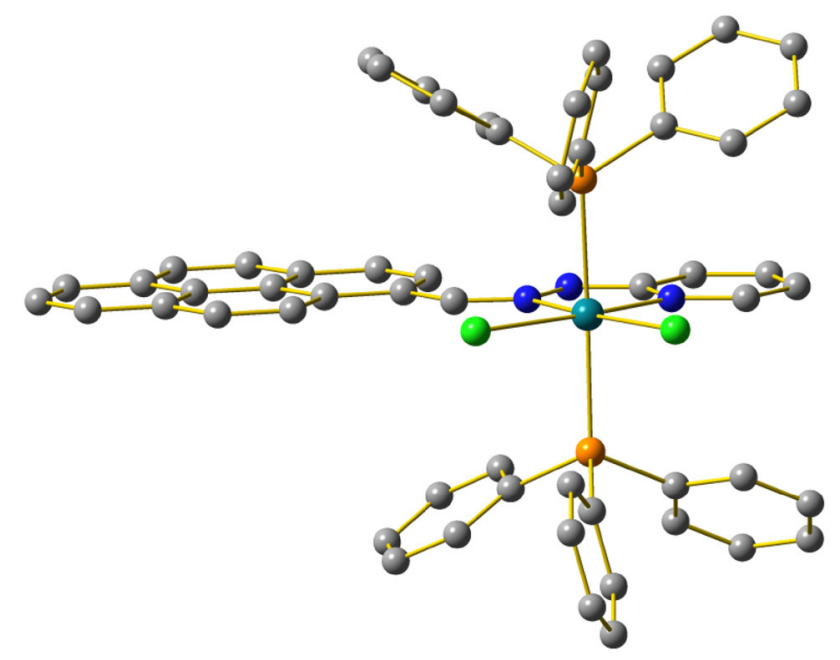

Figure 2. Optimized geometry of $\mathbf{2}$ ( $\mathrm{H}$ atoms are excluded for transparency).

Table 1. Selected average bond lengths and angles obtained by DFT for 2 .

\begin{tabular}{lccc}
\hline Bond distance $(\AA)$ & \multicolumn{2}{c}{ Bond angles $\left(^{\circ}\right)$} \\
\hline Rh1-N1 & 2.06606 & N1-Rh1-Cl2 & 93.26646 \\
Rh1-N3 & 2.08719 & N1-Rh1-N3 & $79.03(7)$ \\
Rh1-Cl1 & 2.44860 & N3-Rh1-Cl1 & 93.81146 \\
Rh1-Cl2 & 2.45038 & Cl1-Rh1-Cl2 & 94.91263 \\
Rh1-P1 & 2.48078 & N1-Rh1-Cl1 & 171.8209 \\
Rh1-P1a & 2.48152 & P1-Rh1-P1a & 174.2204 \\
\hline
\end{tabular}

parameters of $\mathbf{2}$ are generally in good agreement with the experimental values. The HOMO of the compound is essentially composed of $\pi$ MO having a substantial contribution from the pyrene, hydrazone and pyridyl moieties, whereas the LUMO is constituted primarily by triphenylphosphine and rhodium atom, and this set of orbitals are perceptive in their redox behaviour (vide infra). Isodensity plots of some selected orbitals of the Rh(III) complex are portrayed in Figure 3. The partial frontier molecular orbital compositions and energy levels of some selected orbitals (H-5 to L+5) along with the HOMO-LUMO energy gap are listed in Table S4, Supplementary Information.

\subsection{Absorption spectra}

The electronic spectra of the free ligand $\mathbf{1}$ and the chelate 2 were recorded in dichloromethane at room temperature. The spectrum of $\mathbf{1}$ is provided in Figure S1, Supplementary Information while that of $\mathbf{2}$ is portrayed along with its theoretical spectra in Figure 4. Multiple transitions are distinctive of the spectra in the complex 


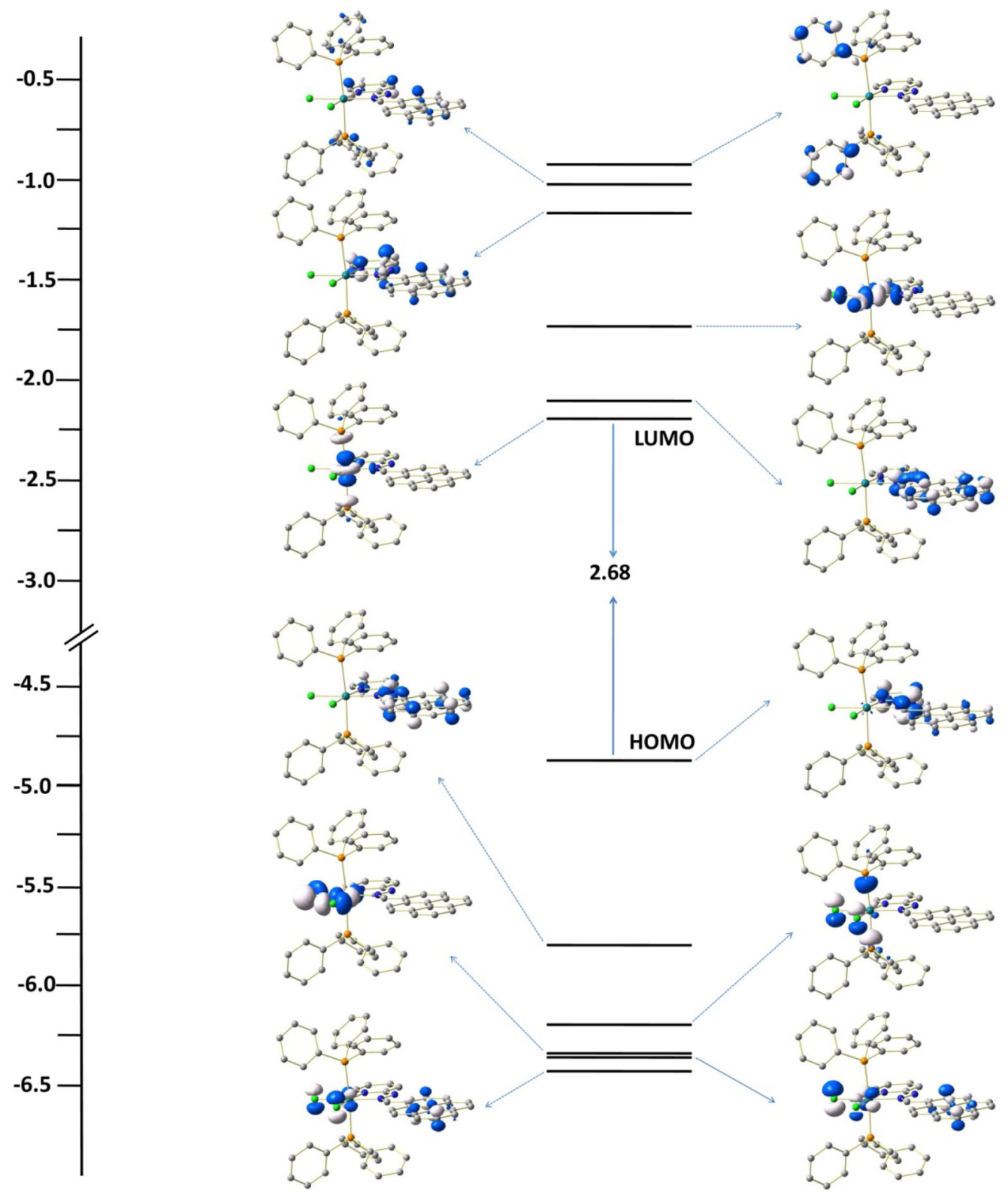

Figure 3. Partial MO diagram and isodensity surface plots of some selected FMOs of 2 (All the energy values are given in $\mathrm{eV}$ ).

and the excitations are ascribed chiefly to the chargetransfer transitions within the bidentate ligand scaffold along with a varying amount of contribution of the metal d-orbitals. In an attempt to have a grasp of the optical absorption processes, we carried out time-dependent density functional theory (TD-DFT) analysis in $\mathrm{CH}_{2} \mathrm{Cl}_{2}$ solvent using the CPCM model. The most pertinent transitions involved, along with the energies, characters and oscillator strengths of the complex are listed in the (Table 2). Natural transition orbital (NTO) analysis was used to examine the origin of the absorption processes and are depicted in SI (Table S5, Supplementary
Information). This method offers the most compact representation of the transition density between the ground and excited states in terms of expansion into single-particle transitions (hole and electron states for each given excitation). In this case, we refer to the unoccupied and occupied NTOs as 'electron' and 'hole' transition orbitals, respectively. In 2, lower energy absorptions in the visible region at 503, 463 and $431 \mathrm{~nm}$ are computed respectively at $507 \mathrm{~nm}(2.445 \mathrm{eV}$, $f=1.031), 495 \mathrm{~nm}(3.287 \mathrm{eV}, f=0.013)$ and $394 \mathrm{~nm}$ $(3.147 \mathrm{eV}, f=0.082)$. The lowest excitation is assigned to $\pi$ (hydrazone) $\rightarrow \mathrm{d}_{z} 2(\mathrm{Rh})+\pi *\left(\mathrm{~N}_{\mathrm{py}}\right)+\mathrm{p}(\mathrm{Cl})$ 


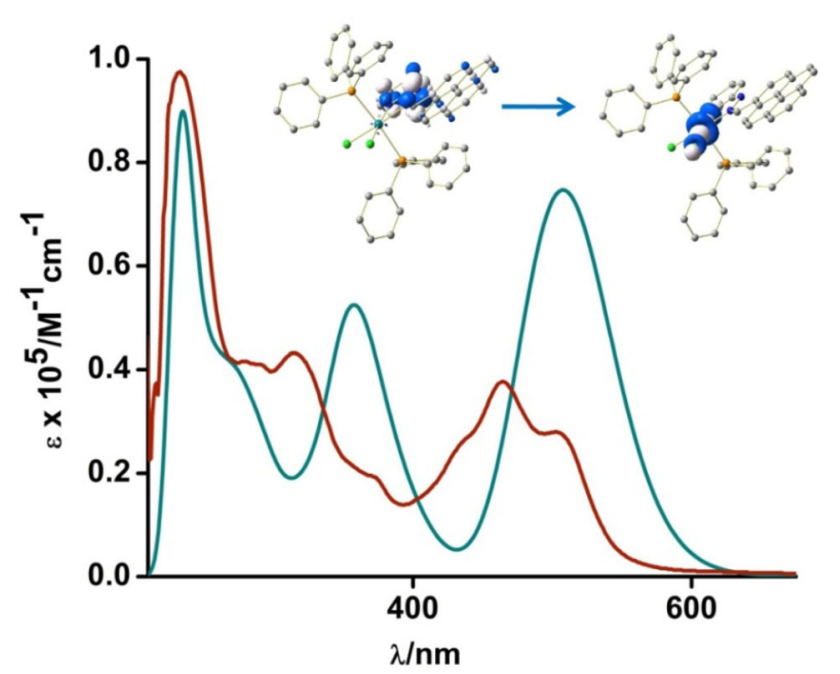

Figure 4. Experimental (red) and theoretical (green) absorption spectra 2 .

essentially ${ }^{1}$ LMCT admixed with some ${ }^{1}$ ILCT $/{ }^{1}$ LLCT character. While the other two are attributed to $3 \mathrm{p}(\mathrm{Cl}) \rightarrow$ $\pi *$ (hydrazone) LLCT and $\pi$ (hydrazone) $\rightarrow \pi *$ (hydrazone) ILCT transition, respectively. The next band near $375 \mathrm{~nm}$ is computed at $357 \mathrm{~nm}(3.472 \mathrm{eV}$, $f=0.204)$ as a $\pi *$ (hydrazone) $\rightarrow \pi *(\mathrm{Ph})^{1}$ ILCT transition. The transition near $313 \mathrm{~nm}(4.095 \mathrm{eV}, f=0.022$, $\lambda_{\text {theo }}=312.0 \mathrm{~nm}$ ) can exclusively be attributed as a $\pi$ (hydrazone) $\rightarrow \mathrm{d}_{z}^{2}(\mathrm{Rh})^{1} \mathrm{LMCT}$ transition. Electronic spectra of the complex exhibit multiple transitions and these excitations are attributed mainly to the chargetransfer transitions within the ligand framework with a varying degree of metal $4 \mathrm{dxz} / 4 \mathrm{dz}^{2}$ contribution in the ground/excited state.

\subsection{Luminescence spectra}

The emission spectral behavior of the ligand and the complex were studied at room temperature in dichloromethane solution. The complex $\mathbf{2}$ upon excitation at the wavelengths where their 1ILCT/1LLCT admixed with ${ }^{1}$ LMCT absorption maxima were observed, exhibit broad luminescent band near $450 \mathrm{~nm}$ (Figure 5) and these remain unaffected with the energy of excitation wavelengths. The ligand and its rhodium(III) complex have been found to behave as moderate emitters (quantum yields $(\Phi)=0.9-1.7 \times$ $\left.10^{-2}\right)$. The emission maxima $\left(\lambda_{e m}\right)$, quantum yield $(\Phi)$, lifetime $(\tau)$, and radiative $\left(\mathrm{k}_{\mathrm{r}}\right)$ and nonradiative $\left(\mathrm{k}_{\mathrm{nr}}\right)$ decay rate constants are summarized in Table 3 . The luminescence spectrum and the time-resolved photoluminescence decay of $\mathbf{1}$ and $\mathbf{2}$ are presented in Figure S2, Supplementary Information.

\subsection{Electrochemistry}

Electron-transfer properties of the rhodium(III) complex was scrutinized by cyclic voltammetry in acetonitrile solution $(0.20 \mathrm{M}[\mathrm{N}(\mathrm{n}-\mathrm{Bu}) 4] \mathrm{PF} 6$ supporting

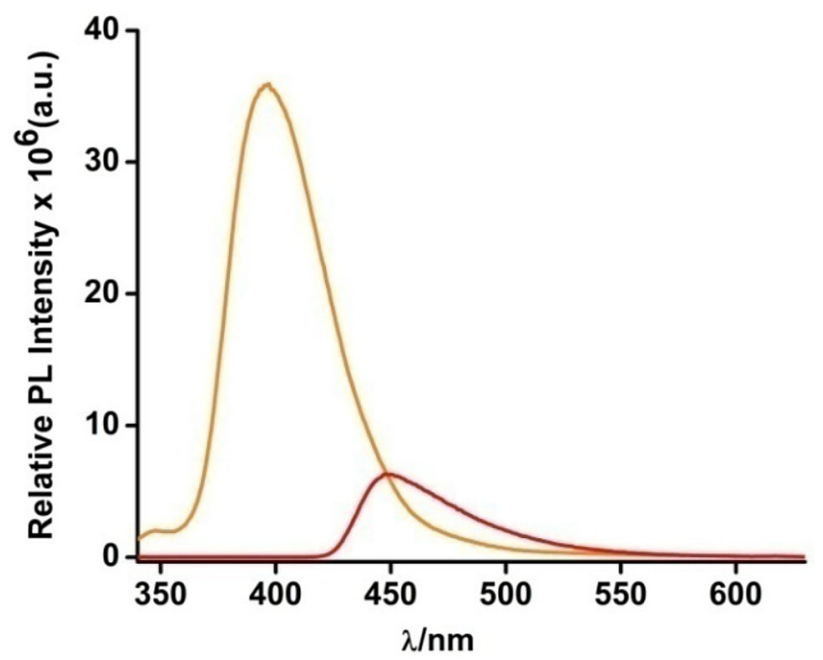

Figure 5. Combined luminescence spectra of HL, 1 (orange), and $\left.\left[\mathrm{RhLPPh}_{3}\right)_{2} \mathrm{Cl}_{2}\right] 2$ (red) in $\mathrm{CH}_{2} \mathrm{Cl}_{2}$ at room temperature.

Table 2. Main optical transition at the TDDFT/B3LYP-6-31G level for the complex 2 with the composition in terms of molecular orbital contribution of the transition, computed vertical energies and oscillator strength in dichloromethane.

\begin{tabular}{|c|c|c|c|c|c|}
\hline Transition & CI & Composition & Energy $(\mathrm{eV})$ & Oscillator strength $(f)$ & $\lambda_{\text {theo }}(\mathrm{nm})$ \\
\hline$S_{0} \rightarrow S_{3}$ & 0.70178 & $\mathrm{HOMO} \rightarrow \mathrm{L}+1(98 \%)$ & 2.4452 & 1.0306 & 507.05 \\
\hline$S_{0} \rightarrow S_{4}$ & 0.64440 & $\mathrm{H}-4 \rightarrow \mathrm{L}+2(83 \%)$ & 2.9252 & 0.0129 & 423.85 \\
\hline$S_{0} \rightarrow S_{7}$ & $\begin{array}{l}0.51200 \\
0.37967\end{array}$ & $\begin{array}{l}\mathrm{HOMO} \rightarrow \mathrm{L}+3(52 \%) \\
\mathrm{H}-1 \rightarrow \mathrm{L}+1(29 \%)\end{array}$ & 3.1465 & 0.0823 & 394.04 \\
\hline$S_{0} \rightarrow S_{14}$ & $\begin{array}{r}0.42823 \\
-0.36827\end{array}$ & $\begin{array}{l}\mathrm{H}-2 \rightarrow \mathrm{L}+2(37 \%) \\
\mathrm{H}-2 \rightarrow \text { LUMO }(27 \%)\end{array}$ & 3.4724 & 0.2047 & 357.05 \\
\hline$S_{0} \rightarrow S_{33}$ & $\begin{array}{l}0.45051 \\
0.38044\end{array}$ & $\begin{array}{l}\mathrm{H}-5 \rightarrow \mathrm{L}+1(41 \%) \\
\mathrm{HOMO} \rightarrow \mathrm{L}+14(29 \%)\end{array}$ & 3.9729 & 0.022 & 312.07 \\
\hline
\end{tabular}


Table 3. UV-Vis and luminescence spectral data for ligand and complex in $\mathrm{CH}_{2} \mathrm{Cl}_{2}$ at room temperature.

\begin{tabular}{llccccc}
\hline Compound & $\lambda_{\max }[\mathrm{nm}]\left(\varepsilon\left[\mathrm{M}^{-1} \mathrm{~cm}^{-1}\right]\right)$ & $\lambda_{\mathrm{em}}(\mathrm{nm})$ & $\tau(\mathrm{ns})$ & $\Phi$ & $k_{\mathrm{r}}, \mathrm{s}^{-1}\left(\times 10^{5}\right)$ & $k_{n \mathrm{r}}, \mathrm{s}^{-1}\left(\times 10^{8}\right)$ \\
\hline $\mathbf{1}$ & $388(64879), 287(35899), 236$ & 401 & $\tau_{1}=2.40$ & 0.019 & 39.014 & 2.014 \\
& $(67629)$ & & & & & \\
$\mathbf{2}$ & $503 \quad(28207), 463(37800)$, & 448 & 5.045 & 0.009 & 17.839 & 1.964 \\
& $431(26689), 375(19387), 313$ & & & & & \\
& & & & & & \\
& & & & & & \\
\end{tabular}

${ }^{\text {a }}$ The compounds $1 \& \mathbf{2}$ are excited at $309 \& 313 \mathrm{~nm}$ respectively.
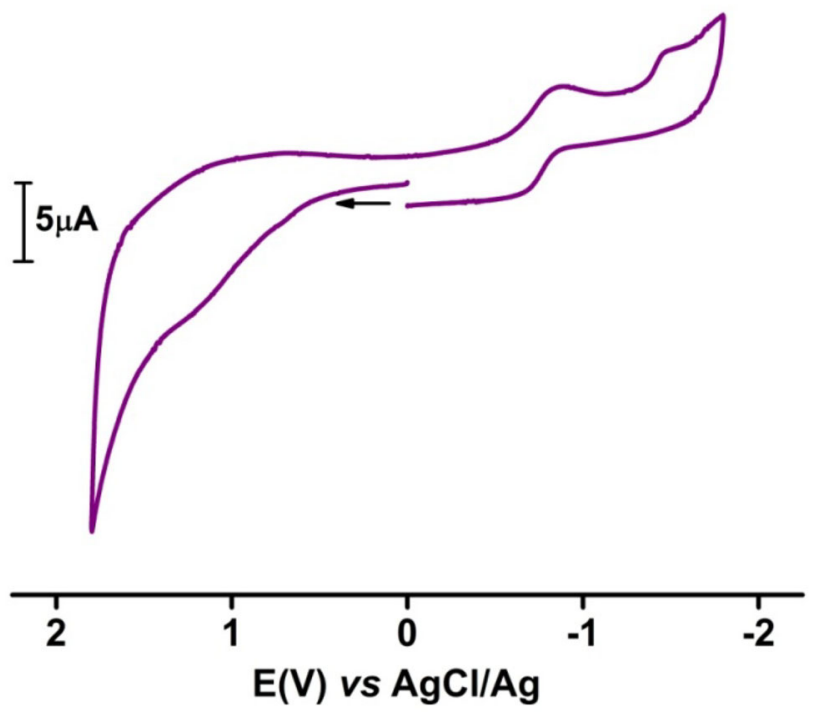

Figure 6. Cyclic voltammogram of $\left[\mathrm{RhL}\left(\mathrm{PPh}_{3}\right)_{2} \mathrm{Cl}_{2}\right]$ (2) (scan rate: 100) in $\mathrm{CH}_{3} \mathrm{CN}$ solvent at 298K. Conditions: $0.20 \mathrm{M}\left[\mathrm{N}(\mathrm{n}-\mathrm{Bu})_{4}\right] \mathrm{PF}_{6}$ supporting electrolyte; platinum working electrode.

electrolyte) by using a platinum working electrode and the reported potential is referenced to $\mathrm{Ag} / \mathrm{AgCl}$ electrode. The value for the ferrocenium/ferrocene couple, under the experimental condition was $0.52 \mathrm{~V}$. The rhodium(III) compound $\mathbf{2}$ was found to be electro-active in solution and exhibit a quasi-reversible one electron reductive couple at -0.7 to $-0.8 \mathrm{~V}$ and an irreversible oxidative couple at $1.2 \mathrm{~V}$ (Figure 6). To investigate the nature of redox orbitals and the underlying electron transfer processes we have performed theoretical studies and it reveals that there is an appreciable metal contribution in LUMO along with some $\sigma^{*}$ of Rh-P bonds (Table S2, Supplementary Information). Reductive responses, therefore, are related with the metal-centred electron transfer processes i.e., primarily an $\mathrm{Rh}(\mathrm{III}) / \mathrm{Rh}(\mathrm{II})$ couple and an additional electron enters into the vacant $4 \mathrm{~d}_{z} 2 \mathrm{AO}$ during the course of reduction. This attribution is apparent from the energetically high-lying nature of vacant ligand-based orbitals in typical Schiff base ligand viz., LUMO+1 in comparison to that of the metalrich LUMO. This is due to the fact that ligand scaffold is composed primarily of conjugated imine along with weak electron deficient pyridyl and hydrazonyl moieties. On the contrary, the HOMO is constituted by the $\mathrm{p}_{\pi}$ orbitals, encompassing the entire ligand backbone (hydrazone $35 \%$ pyrene $37 \%$ and pyridyl 27\%), with practically no participation from metal AOs. Thus the oxidative couple at $1.2 \mathrm{~V}$ can be attributed to an exclusive ligand-centred oxidation process.

\section{Conclusions}

A new ligand (HL, 1) containing $\pi$-acidic pyridine functionalized hydrazone in conjunction with the polycyclic aromatic hydrocarbon (PAH), pyrene has been suitably designed and synthesized. It was further treated with Wilkinson catalyst to synthesize the complex 2 via an oxidative coordination reaction. The complex displays rich spectral features in the UV-vis region and its redox active character has been validated from the well-defined responses at mild potentials as well as from the theoretical analysis. The ligand is emissive and its complex with $\mathrm{Rh}(\mathrm{III})$ has been also found to be moderately emissive with a slight quenching of the emission quantum yield as compared to that of the free ligand. The molecular and electronic structures, optoelectronic behaviour as well as the nature of the emitting excited state have been authenticated by density functional theory (DFT) and time-dependent density functional theory (TD-DFT).

\section{Supplementary Information (SI)}

CCDC contains the supplementary crystallographic data for this paper with a deposition number of CCDC 1831093 for 2. This data can be obtained free of charge at www. ccdc.cam.ac.uk/conts/retrieving.html [or from the Cambridge Crystallographic Data Centre, 12, Union Road, Cambridge CB2 1EZ, UK; fax: (internet.) +44-1223/336-033; E-mail: deposit@ccdc.cam.ac.uk. 


\section{Acknowledgements}

We are thankful to the State Council for Science and Technology, West Bengal (Grant No. 683(Sanc.)/ST/P/S\&T/ 4G-11/2014) for their financial support. We express our deep sense of gratitude to Prof. Kausikisankar Pramanik of Jadavpur University for permitting us to use all the instrumental facilities of his laboratory. Grants from DST-FIST for the instrumental facility in SXC are gratefully acknowledged. We express our sincere thanks to the Department of Science and Technology, New Delhi, India for the data collection on the CCD facility setup (Jadavpur University). S. Dinda acknowledges WBDST for his research fellowship. S. C. Patra thanks UGC, New Delhi (No. F. 4-2/2006(BSR)/CH/15-16/0173) for his fellowship.

\section{References}

1. Pramanik S and Aprahamian I 2016 Hydrazone SwitchBased Negative Feedback Loop J. Am. Chem. Soc. 138 15142

2. Su X and Aprahamian I 2013 Zinc(II)-Regulation of Hydrazone Switch Isomerization Kinetics Org. Lett. 15 5952

3. Krishnamoorthy P, Sathyadevi P, Butorac R R, Cowley A H, Bhuvanesh N S P and Dharmaraj N 2012 Variation in the biomolecular interactions of nickel(II) hydrazone complexes upon tuning the hydrazide fragment Dalton Trans. 416842

4. Su X and Aprahamian I 2014 Hydrazone-based switches, metallo-assemblies and sensors Chem. Soc. Rev. $\mathbf{4 3} 1963$

5. Angelusiu M V, Barbuceanu S F, Draghici C and Almajan G L 2010 New Cu(II), Co(II), Ni(II) complexes with aroyl-hydrazone based ligand. Synthesis, spectroscopic characterization and in vitro antibacterial evaluation Eur. J. Med. Chem. 452055

6. Kobayashi A, Dosen M, Chang M, Nakajima K, Noro S and Kato M 2010 Synthesis of Metal-Hydrazone Complexes and Vapochromic Behavior of Their HydrogenBonded Proton-Transfer Assemblies J. Am. Chem. Soc. 13215286

7. Naskar S, Naskar S, Butcher R J and Chattopadhyay K $\mathrm{S} 2010$ Synthesis and spectroscopic properties of $\mathrm{Ni}(\mathrm{II})$ complexes of some aroyl hydrazone ligands with 2,6diacetyl pyridine monooxime: X-ray crystal structure of the salicyloylhydrazone $\mathrm{Ni}(\mathrm{II})$ complex Inorg. Chim. Acta 363404

8. Aslan H G, Ozcan S and Karacan N 2011 Synthesis, characterization and antimicrobial activity of salicylaldehyde benzenesulfonylhydrazone (Hsalbsmh)and its Nickel(II), Palladium(II), Platinum(II), Copper(II), Cobalt(II) complexes Inorg. Chem. Commun. 141550

9. Wang Q, Yang Z Y, Qi G F and Qin D D 2009 Crystal structures, DNA-binding studies and antioxidant activities of the Ln(III) complexes with 7methoxychromone3-carbaldehyde-isonicotinoyl hydrazone BioMetals 22927

10. Xu Z, Zhang X, Zhang W, Gao Y and Zeng Z 2011 Synthesis, characterization, DNA interaction and antibacterial activities of two tetranuclear cobalt(II) and nickel(II) complexes with salicylaldehyde 2-phenylquinoline-4carboylhydrazone Inorg. Chem. Commun. 141569

11. Kratz F, Beyer V, Roth T, Tarasova N, Collery P, Lechenault F, Cazabat A, Shumacher P, Unger C and Falkem U 1998 Transferrin Conjugates of Doxorubicin: Synthesis, Characterization, Cellular Uptake, and in Vitro Efficacy J. Pharm. Sci. 87338

12. Li Y, Yang Z, Zhoua M and Li Y 2017 Synthesis and crystal structure of new monometallic Ni(II) and $\mathrm{Co}(\mathrm{II})$ complexes with an asymmetrical aroylhydrazone: effects of the complexes on DNA/protein binding property, molecular docking, and in vitro anticancer activity $R S C$ Adv. 749404

13. Jayanthi E, Kalaiselvi S, Padma V V, Bhuvanesh N S $\mathrm{P}$ and Dharmaraj N 2016 Solvent assisted formation of ruthenium(III) and ruthenium(II) hydrazone complexes in one-pot with potential in vitro cytotoxicity and enhanced LDH, NO and ROS release Dalton Trans. 45 1693

14. Sathyadevi P, Krishnamoorthy P, Butorac R R, Cowley A H and Dharmaraj N 2012 Synthesis of novel heterobimetallic copper(I) hydrazone Schiff base complexes: A comparative study on the effect of heterocyclic hydrazides towards interaction with DNA/protein, free radical scavenging and cytotoxicity Metallomics $\mathbf{4}$ 498

15. Krishnamoorthy P, Sathyadevi P, Butorac R R, Cowley A H, Bhuvanesh N S P and Dharmaraj N 2012 Copper(I) and nickel(II) complexes with 1:1 vs. 1:2 coordination of ferrocenyl hydrazone ligands: Do the geometry and composition of complexes affect DNA binding/cleavage, protein binding, antioxidant and cytotoxic activities? Dalton Trans. $\mathbf{4 1} 4423$

16. Palepu N R and Kollipara M R 2017 Half-sandwich ruthenium, rhodium and iridium complexes of triazolopyridine ligand: Synthesis and structural studies $J$. Chem. Sci. 129177

17. Singh K S, Wang P, Narkhede N A and Mozharivskyj Y 2017 Iridium(III) and Rhodium(III) compounds of dipyridyl-N-alkylimine and dipyridyl-NH-ketimine: Spectral characterization and crystal structure J. Chem. Sci. 129365

18. Palepu N R, Kaminsky W and Kollipara M R 2017 Synthesis and structural studies of half-sandwich $\mathrm{Cp}^{*}$ rhodium and $\mathrm{Cp}^{*}$ iridium complexes featuring mono, bi and tetradentate nitrogen and oxygen donor ligands $J$. Chem. Sci. 129561

19. Katual M and Dutt G 1975 Analytical applications of hydrazones Talanta 22151

20. Franceschelli J J, Belardinelli M J, Tong P, Loftus B, Recio-Balsells A, Labadie G R, Gordon S V and Morbidoni H 2018 A katG S315T or an $a h p C$ promoter mutation mediate Mycobacterium tuberculosis resistance to 2-thiophen carboxylic acid hydrazide, an inhibitor resembling the anti-tubercular drugs Isoniazid and Ethionamide Tuberculosis 11269

21. Mishra M, Tiwari K, Shukla S, Mishra R and Singh V P 2014 Synthesis, structural investigation, DNA and protein binding study of some 3d-metal complexes with N/-(phenyl-pyridin-2-yl-methylene)-thiophene-2carboxylic acid hydrazide Spectrochim. Acta Part A 132 452 
22. Ravesh A and Malhotra R 2018 Synthesis, Characterization and Antimicrobial Screening of Organotin (IV) complexes derived from Schiff bases of Pyrazine2-carboxylic acid hydrazide Asian J. Res. Chem. 11 262

23. Mallandur $\mathrm{K}$ B, Rangaiah and Harohally $\mathrm{K} \quad \mathrm{N}$ 2017 Synthesis and antimicrobial activity of Schiff bases derived from 2-chloro quinoline-3-carbaldehyde and its derivatives incorporating 7-methyl-2-propyl$3 \mathrm{H}$-benzoimidazole-5-carboxylic acid hydrazide Synth. Commun. 471065

24. Xu P, Wang G, Wu Z, Li S and Zhu C 2017 Rh(III)catalyzed double $\mathrm{C}-\mathrm{H}$ activation of aldehyde hydrazones: a route for functionalized $1 \mathrm{H}$-indazole synthesis Chem. Sci. 81303

25. Chuang S, Gandeepan P and Cheng C 2013 Synthesis of isoquinolines via $\mathrm{Rh}(\mathrm{III})$-catalyzed $\mathrm{C}$-H activation using hydrazone as a new oxidizing directing group Org. Lett. 155750

26. Zheng L and Hua R 2014 Rhodium(III)-Catalyzed C$\mathrm{H}$ activation and indole synthesis with hydrazone as an auto-formed and auto-cleavable directing group Chem. Eur. J. 202352

27. Dawson W R and Windsor M W 1968 Fluorescence Yields of Aromatic Compounds J. Phys. Chem. 723251 and references therein

28. Meech S R and Phillips D 1983 Photophysics of some common fluorescence standards J. Photochem. 23193 and references therein

29. Van Houten J and Watts R J 1976 Temperature dependence of the photophysical and photochemical properties of the tris(2,2'-bipyridyl)ruthenium(II) ion in aqueous solution J. Am. Chem. Soc. 984853

30. Sheldrick G M 2003 SHELXTL v. 6.14; Bruker AXS Inc.: Madison, WI

31. Johnson C K ORTEP report ORNL-5138, Oak Ridge National Laboratory, Oak Ridge, TN, 976.

32. Becke A D 1993 Density-functional thermochemistry. III. The role of exact exchange J. Chem. Phys. 98 5648

33. Lee C, Yang W R and Parr G 1988 Development of the colle-salvetti correlation-energy formula into a functional of the electron density Phys. Rev. B: Condens. Matter 37785

34. Frisch M J, Trucks G W, Schlegel H B, Scuseria E, Robb M A, Cheeseman J R, Scalmani G, Barone V, Mennucci B, Petersson G A, Nakatsuji H, Caricato M, Li X, Hratchian H P, Izmaylov A F, Bloino J, Zheng G, Sonnenberg J L, Hada M, Ehara M, Toyota K, Fukuda R, Hasegawa J, Ishida M, Nakajima T, Honda Y, Kitao O, Nakai H, Vreven T, Montgomery J A, Jr, Peralta J E, Ogliaro F, Bearpark M, Heyd J J, Brothers E, Kudin K N, Staroverov V N, Kobayashi R, Normand J, Raghavachari K, Rendell A, Burant J C, Iyengar S S, Tomasi J, Cossi M, Rega N, Millam J M, Klene M, Knox J E, Cross J B, Bakken V, Adamo C, Jaramillo J, Gomperts R, Stratmann R E, Yazyev O, Austin A J, Cammi R, Pomelli C, Ochterski J W, Martin R L, Morokuma K, Zakrzewski V G, Voth G A, Salvador P, Dannenberg J J, Dapprich S, Daniels A D, Farkas Ö, Foresman J B, Ortiz J V, Cioslowski J and Fox D J 2009 Gaussian, Inc., Wallingford CT,GAUSSIAN 09 (Revision A.01)
35. Autschbach J, Ziegler T, Gisbergen S J A and Baerends E J 2002 Chiroptical properties from time-dependent density functional theory. I. Circular dichroism spectra of organic molecules J. Chem. Phys. 1166930

36. Bak K L, Jørgensen P, Helgaker T, Ruud K and Jensen H J A 1993 Gauge-origin independent multiconfigurational self-consistent-field theory for vibrational circular dichroism J. Chem. Phys. 988873

37. Helgaker T and Jørgensen P 1991 An electronic hamiltonian for origin independent calculations of magnetic properties J. Chem. Phys. 952595

38. Gross E K U and Kohn W 1990 Time-dependent densityfunctional theory Adv. Quantum Chem. 21255

39. Cossi M, Rega N, Scalmani G and Barone V J 2003 Energies, structures, and electronic properties of molecules in solution with the CPCM solvation model J. Comput. Chem. 2466939.

40. Barone V and Cossi M 2001 Time-dependent density functional theory for molecules in liquid solutions $J$. Chem. Phys. 1154708

41. Barone V and Cossi M 1998 Quantum calculation of molecular energies and energy gradients in solution by a conductor solvent model J. Phys. Chem. A 102

42. Liu T, Zhang H X and Xia B H 2007 Theoretical studies on structures and spectroscopic properties of a series of novel cationic $\left[\text { trans }-\left(\mathrm{C}^{\wedge} \mathrm{N}\right)_{2} \operatorname{Ir}\left(\mathrm{PH}_{3}\right)_{2}\right]^{+}\left(\mathrm{C}^{\wedge} \mathrm{N}=\right.$ ppy, bzq, ppz, dfppy) J. Phys. Chem. A 1118724

43. Albertino A, Garino C and Ghiani S 2007 Photophysical properties and computational investigations of tricarbonylrhenium(I)[2-(4-methylpyridin-2-yl)benzo[ $d]-\mathrm{X}$ azole $] \mathrm{L}$ and tricarbonylrhenium(I)[2-(benzo $[d]-\mathrm{X}$-azol2-yl)-4-methylquinoline]L derivatives ( $\mathrm{X}=\mathrm{N}-\mathrm{CH}_{3}$, $\mathrm{O}$, or $\mathrm{S} ; \mathrm{L}=\mathrm{Cl}^{-}$, pyridine) J. Organomet. Chem. 692 1377

44. Zhou X, Zhang H X, Pan Q J, Xia B H and Tang A C 2005 Theoretical studies of the spectroscopic properties of $[\mathrm{Pt}(\operatorname{trpy}) \mathrm{C}: \mathrm{CR}]^{+}$(trpy = 2,2',6',2'-terpyridine; $\mathrm{R}=$ $\mathrm{H}, \mathrm{CH}_{2} \mathrm{OH}$, and $\mathrm{C}_{6} \mathrm{H}_{5}$ ) J. Phys. Chem. A 1098809

45. Zhou X, Ren A M and Feng J K 2005 Theoretical studies on the ground states in $\mathrm{M}$ (terpyridine $)_{2}^{2+}$ and $\mathrm{M}$ (n-butyl-phenylterpyridine $)_{2}^{2+}(\mathrm{M}=\mathrm{Fe}, \mathrm{Ru}, \mathrm{Os})$ and excited states in $\mathrm{Ru}$ (terpyridine $)_{2}^{2+}$ using density functional theory J. Organomet. Chem. 690338

46. Hay P J and Wadt W R 1985 Ab initio effective core potentials for molecular calculations. Potentials for K to Au including the outermost core orbitals J. Chem. Phys. 82299

47. Hay P J and Wadt W R 1985 Ab initio effective core potentials for molecular calculations. Potentials for the transition metal atoms Sc to Hg J. Chem. Phys. 82270

48. Gordon M S, Binkley J S, Pople J A, Pietro W J and Hehre W J 1982 Self-consistent molecular-orbital methods. 22. small split-valence basis sets for second-row elements $J$. Am. Chem. Soc. 1042797

49. Binkley J S, Pople J A and Hehre W J 1980 Selfconsistent molecular-orbital methods. 21. small splitvalence basis sets for second-row elements J. Am. Chem. Soc. 102939

50. O'Boyle N M, Tenderholt A L and Langne K M 2008 cclib: A library for package-independent computational chemistry algorithms J. Comput. Chem. 29839 